\title{
There will be blood
}

\section{Direct conversion of cell types could offer safer, simpler treatments than stem cells.}

\section{BY EWEN CALLAWAY}

$\mathrm{I}$ $\mathrm{n}$ a feat of cellular alchemy, human skin cells have been transformed into blood cells without first being sent through a primordial, stem-cell-like state. For the developers of patient-specific cell therapies, the result could be safer and simpler than induced pluripotent stem (iPS) cells - reprogrammed adult cells that can differentiate into many cell types.

Published in Nature ${ }^{1}$, the study follows work earlier this year showing that fibroblast cells from mouse skin can be transformed into neurons ${ }^{2}$ and heart muscle ${ }^{3}$. However, it is the first study to accomplish direct reprogramming with human cells, and the first to create

$\rightarrow$ NATURE.COM For a longer version of this story, see: go.nature.com/ekshcj progenitor cells - in this case for blood. "It takes us a step along the line to believing that you can produce anything from almost anything," says Ian Wilmut, director of the Medical Research Council Centre for Regenerative Medicine in Edinburgh, UK, who was not involved in the study.

Mickie Bhatia, a stem-cell researcher at McMaster University in Hamilton, Canada, and his colleagues infected skin cells with a virus that inserted the OCT4 gene, then they grew the cells in a soup of immune-system stimulating proteins called cytokines. The gene's product, the OCT4 protein, is one of a handful of factors used to transform fibroblasts into iPS cells, but Bhatia's team found no evidence that the blood progenitor cells they made went through an embryonic state. For instance, the cells did not cause mice to develop teratomas - tumours that are characteristic of pluripotent cells, making iPS cells less attractive as a therapeutic option. The progenitors did, however, produce all three classes of blood cells - white, red and platelets - all of which were functional. The red blood cells also produced the adult form of haemoglobin, whereas iPS-cell-derived blood cells make the fetal form. "This is the most encouraging result we've seen for using blood cells for cell-replacement therapy," says Bhatia.

Converted cells aren't without their drawbacks, though. Unlike iPS and embryonic stem cells, they cannot easily multiply in the lab, so producing the large quantities needed for screening drugs, for example, could be difficult, says Wilmut. It is also too early to tell whether they will be as good as the real thing when inside a person, says George Daley, a stem-cell biologist at Children's Hospital Boston in Massachusetts. Transplanting the cells into humans is still years away, says Bhatia. "The clinical side is going to be a lot of work."

1. Szabo, E. et al. Nature advance online publication doi:10.1038/nature09591 (2010)

2. Vierbuchen, T. et al. Nature $463,1035-1041$ (2010). 3. leda, M. et al. Cell 142, 375-386 (2010).

\section{CORRECTION}

The News Feature 'The telescope that ate astronomy' (Nature 467, 1028-1030; 2010) wrongly said that a revised budgetary plan for the James Webb Space Telescope could come as early as 2 November. In fact, the plan is not likely to be unveiled before the president's budget request in February 2011. 